\title{
No more scavenger hunts
}

\author{
The recent media flap over antidepressants highlights the need for data to be transparent - and for a \\ mandatory database of all clinical trials.
}

t t was not the media's finest hour. When a study was released last week challenging the effectiveness of several popular antidepressant drugs, some news outlets, particularly in the United Kingdom, responded with headlines blaring 'the drugs don't work' - even though the drugs often do work. Yes, the study showed that the drugs often performed no better than a placebo. But what many of the media missed was that the placebo effect can be remarkably strong in psychological and neurological disorders, especially in mild depression. Doctors scrambled to assure patients that they should not abandon treatment.

Almost buried in the hubbub, though, was a more important story. To access the data needed for this study - a meta-analysis of 35 clinical trials - the researchers had to file a Freedom of Information Act request with the US Food and Drug Administration. And the information they finally received was incomplete: crucial data were missing for several studies that failed to find a significant benefit of the drug compared with the placebo. The missing data limited the analysis, and forced the researchers to abandon their investigation of two drugs altogether.

Such data chaos has become all too familiar in the world of clinical trials. And that fact, combined with recent scandals about antidepressants, diabetes drugs and cholesterol medications, has spurred an outcry to make clinical-trial registries mandatory.

That outcry has not been ignored - the past few years have seen dramatic improvements in data transparency. The International Committee of Medical Journal Editors took a valuable step forward in 2004 when it demanded that authors list and describe their clinical trials in an accepted registry. The number of clinical trials registered in the US National Institutes of Health database rose from 13,153 to 22,714 in a single month, and now stands at more than 52,000 trials spanning 153 countries. Other databases are also active, including an international trial registry hosted by the World Health Organization,

which has declared the registration of all interventional trials a "scientific, ethical and moral responsibility".

That responsibility remains unfulfilled. The existing databases are neither comprehensive nor mandatory. Researchers in search of clinical-trial data still have to embark on a scavenger hunt through missing trials and incomplete database entries. Yet the taste of success has been enough to move some open-access advocates to the next step: asking for a description not only of a trial's protocol, but also its results.

Critics argue that results databases could undermine the peer-review process, reveal competitive information or enable sloppy meta-analyses that set off public panics. They have a point: public registries are no substitute for peerreviewed literature. But such results

"Researchers still have to embark on a scavenger hunt through missing trials and incomplete database entries." databases would still serve an important purpose - as repositories for the negative data that often go unpublished, but that can reveal a drug or treatment regime as ineffective. These data are crucial for meta-analyses, and could improve the design of subsequent trials. Despite reluctance by some pharmaceutical companies to participate, the registries could be helpful to them.

So what can be done to encourage recalcitrant investigators to deposit their data? Several prominent medical journals have removed one barrier by reassuring authors that depositing an abstract or table of results will not be considered 'prior publication'. Politicians in several countries have expressed interest in mandating clinical-trial registries, with some emphasizing the importance of depositing trial results as well. But true fulfilment of that moral responsibility will require international cooperation and enforcement by regulatory authorities - an unprecedented degree of organization and commitment. It is a daunting goal, but one worthy of the struggle.

\section{Time to connect}

\section{More than ever, academics in Iran and in nations hostile to it should communicate with each other.}

T his week's address by Mohamed ElBaradei, director-general of the International Atomic Energy Agency (IAEA), to the 35 member states on the agency's governing board highlighted the urgent need for Iran to allow the agency broader inspection powers. But it also highlighted the importance of continuing constructive dialogue amid the bellicose words of national leaders.

There is plenty to alienate Western countries on the one hand and Iran on the other. Iranian President Mahmoud Ahmadinejad's threats against Israel, the nation's fatwa against the writer Salman Rushdie and current domestic violations of human rights are deplorable. But many in the West are ignorant of the depth of resentment, even among the most moderate Iranians, at Western foreign policy in the region. Particularly remembered are the 1953 overthrow by the United States and Britain of the elected government of Mohammed Mossadegh after he nationalized the AngloIranian Oil Company, and the decades of despotic rule that ensued under the Shah.

Nevertheless, Iran's current hard-line leadership masks the county's rich veins of democracy, education and free thinking, which are more developed than those of most of its neighbours in the Middle East. Moreover, Iranian and US politics are both more diverse and pragmatic towards foreign policy than the respective presidents are. 
Détente is no longer inconceivable as the national interests - the driver of Realpolitik - of both converge, not least in Iraq.

But as tensions run high, academics on all sides can try and help defuse them. Some, in particular physicists, are already active in back-channel diplomacy, encouraging détente by opening up informal, person-to-person communications that bypass their stiff-necked leaders. The US National Academy of Sciences is also expanding scientific cooperation and dialogue with Iran. Such efforts are to be applauded.

A crucial imperative is to find a way out of the international crisis over Iran's nuclear programme. Academics have a role here, too. From historians and nuclear physicists to national academies, they can help to elevate the level of debate above that conveyed by Fox News or Iran's state television. They can explain the complex geopolitical realities that have led to the current escalation, but also inject much-needed scientific facts and objectivity into the debates about the purposes of Iran's nuclear efforts.

It is important to unpack the issues. Iran needs to come clean on any past military aims. But the key challenge is to deal with the here and now: regimes' past intents can be changed by forceful diplomacy. Many nuclear experts argue that the most important goal is for the international community to have confidence that Iran's current programme is not diverted to military ends. And so the priority is to persuade Iran to agree to the 1997 'additional protocol' to the IAEA's safeguards agreement. The protocol gives the agency extra powers, such as short-notice inspections of any site - not just of declared nuclear facilities - and so guards against the biggest worry: clandestine diversion of nuclear expertise.

Iran has not ratified the additional protocol, although it voluntarily allowed equivalent broad access from May 2004 to January 2006. But after United Nations resolutions required it to suspend uranium enrichment, Iran stopped its extended cooperation with the IAEA, and reaped popular domestic support in the process by portraying the actions as foreign threats to their right to nuclear energy.

Earlier this week the United Nations Security Council agreed to further sanctions against Iran in the hope of forcing a suspension of enrichment. Such an aim is indeed desirable for many reasons, but an insistence that there can be no negotiations until Iran ceases enrichment is futile and counterproductive. A negotiated solution would strengthen the hand of reformers in Iran, because it would dilute Ahmadinejad's ability to wield external threats and divert domestic attention from his dire human-rights and economic record.

Many of Iran's democratic forces have their roots in a vibrant scientific community, which too often has been subjected to humiliating visa refusals and actively or passively ostracized by colleagues elsewhere. An experiment for Iranian and US scientists: follow the example of fellow researchers, find a counterpart in your field, and connect with them.

\section{The EPA's tailspin}

\section{The director of the Environmental Protection Agency is sabotaging both himself and his agency.}

\footnotetext{
7
} he US Environmental Protection Agency (EPA) is fast losing the few shreds of credibility it has left. The Bush administration has always shown more zeal in protecting business interests than the environment (see Nature 447, 892-893; 2007). But the agency's current administrator, Stephen Johnson, a veteran EPA toxicologist who was promoted to the top slot in 2005, has done so with reckless disregard for law, science or the agency's own rules - or, it seems, the anguished protests of his own subordinates.

On 27 February, to take the first of two examples that surfaced last week, Senator Barbara Boxer (Democrat, California) used a routine budget hearing to give Johnson a grilling. Why hadn't he given her state permission to regulate the carbon dioxide emissions of vehicle exhausts? California needs a waiver from the EPA to regulate in this way, and in the past such waivers have been granted easily. And, Boxer reminded him via a series of leaked memos and PowerPoint presentations, Johnson's own top-level staff begged him to sign the waiver in this case. "This is a choice only you can make," one colleague wrote to him. "But I ask you to think about the history and the future of the agency in making it. If you are asked to deny this waiver, I fear the credibility of the agency that we both love will be irreparably damaged."

In December, Johnson announced he would refuse the waiver, an act that would also deny permission to more than a dozen other states seeking to base their exhaust regulations on California's. Johnson argued that climate change is not a local phenomenon, so dealing with it isn't what the authors of the Clean Air Act intended for the waiver system.

Although logical, this argument is similar to that made by Johnson's EPA in an earlier case involving Massachusetts, when the agency fought against $\mathrm{CO}_{2}$ regulation all the way to the Supreme Court - and lost. His insistence on using it again can perhaps best be understood from the fact that Johnson answers to a White House that is hostile to regulation on principle. It is also worth noting that his refusal documentation, made official on 29 February, extensively quotes an industry trade association, the Alliance of Automobile Manufacturers.

The second example came on 29 February, in the form of a joint letter to Johnson from the four labour unions representing most of the EPA's professional staff. Listing examples of alleged bad faith by Johnson, the unions essentially refused to work with him until he cleans up his act. Among the complaints was an assertion that he repeatedly ignored the EPA's official Principles of Scientific Integrity, citing "fluoride drinking water standards, organophosphate pesticide registration, control of mercury emissions from power plants" - and the waiver refusal.

In a rational world, Johnson would resign in favour of someone who could at least feign an interest in the environment. Alas, it seems that he will probably stay on until January 2009 , refusing waivers, fighting lawsuits and further depressing employees' morale. In the meantime, we can only offer those employees a fantasy: the White House doesn't want the agency to do anything, so shut it down until next January. Take some fully paid sabbatical time to relax, and prepare for a return to the old-fashioned protecting of the environment that so many of you joined the agency for. 